\title{
FAMILY HISTORY OF LOW BACK PAIN IS A SIGNIFICANT PREDICTOR OF PAIN AND DISABILITY BETWEEN EXTREME STAGES OF LUMBAR DISC DEGENERATION
}

Samartzis D, ${ }^{1}$ Bow C, ${ }^{1}$ Karppinen $J,{ }^{2}$ Luk KDK, ${ }^{1}$ Cheung BMY, ${ }^{3}$ Cheung $K M C^{l}$

${ }^{1}$ Department of Orthopaedics and Traumatology, The University of Hong Kong, Hong Kong ${ }^{2}$ Institute of Clinical Medicine, University of Oulu, Oulu, Finland ${ }^{3}$ Department of Medicine, The University of Hong Kong, Hong Kong

INTRODUCTION: This large-scale population-based study addressed the role of magnetic resonance imaging (MRI) findings, lifestyle / environmental / cardiovascular factors, and low back pain (LBP) family history in extreme stages of lumbar disc degeneration (i.e. nondegenerated [normal] vs. moderate / severe disc degeneration) on MRI as well as LBP occurrence.

METHODS: This was a cross-sectional study of the Hong Kong Disc Degeneration-

Cardiovascular Cohort which composed of 1800 Southern Chinese volunteers. The study entailed 2 groups: Group $1(n=229)$ included non-degenerated discs and Group $2(n=335)$ included moderate / severe global disc degeneration. Blood chemistry, anthropometric, lifestyle / environmental as well as pain profiles were obtained.

RESULTS: In Group 1, multivariate regression modelling noted that LBP family history (odds ratio [OR], 3.80; 95\% confidence interval [95\% CI], 1.43-10.04; $\mathrm{p}=0.007)$, younger age (0.92; $0.89-1.01 ; \mathrm{p}=0.069)$, and elevated high-sensitivity $\mathrm{C}$-reactive protein $(1.26 ; 0.91-1.73 ; \mathrm{p}=0.17)$ were related to LBP. Regarding Group 2, multivariate regression model noted that male gender $(14.84 ; 1.30-169.70 ; \mathrm{p}=0.030)$, younger age $(0.80 ; 0.68-0.96 ; \mathrm{p}=0.014)$, and elevated erythrocyte sedimentation rate $(1.11 ; 1.01-1.23 ; \mathrm{p}=0.032)$ were significantly associated with LBP. The LBP family history was the predominant factor significantly associated with abnormal functional / disability scores in both groups $(\mathrm{p}<0.05)$.

CONCLUSIONS: This study illustrated for the first time why certain individuals developed LBP, irrespective of MRI findings, which largely attributed to LBP family history. 